\title{
Comparison of the effect of mesh-plug, Lichtenstein, transabdominal preperitoneal, and totally extraperitoneal hernia repair: A network meta-analysis
}

\author{
(D) Yi-Hua Shi ${ }^{1}$ \\ (D) De-Shuang Xiao' \\ (iD Ling-Bo Dai ${ }^{1}$ \\ (iD) Qian Fang1
}

1. Department of General Surgery, The First People's Hospital of Wenling, Wenling, 234000 , Zhejiang Province, China.

http://dx.doi.org/10.1590/1806-9282.66.5.687

\section{SUMMARY}

OBJECTIVE: To compare Mesh-plug, Lichtenstein, transabdominal preperitoneal (TAPP), and totally extraperitoneal (TEP) repairs in regards to operation time, seroma, infection, and recurrence of inguinal hernia repair.

METHODS: Relevant literature was searched in the Cochrane Library, Pubmed, and Embase. Furthermore, the analysis of randomized controlled studies (RCTs) was performed using methods recommended by the Cochrane Collaboration. The main outcomes including operation time, seroma, infection, and recurrence were evaluated.

RESULTS: A total of 38 RCTs with 3255 patients were included in the meta-analysis. In addition, the comparison between Mesh-plug, Lichtenstein, TAPP, and TEP showed the differences were not significant regarding operation time, seroma, infection, and recurrence.

CONCLUSIONS: Meta-analysis suggests that Mesh-plug, Lichtenstein, TAPP, and TEP are comparable in the outcomes of hernia repair, such as operation time, seroma, infection, and recurrence.

KEYWORDS: Hernia, inguinal/surgery. Treatment outcome. Herniorrhaphy. Surgical mesh. Meta-Analysis.

\section{INTRODUCTION}

Hernias are generally weaknesses or defects of the muscle fibers that occur through the abdominal wall and provide a body cavity for the protrusion of internal organs ${ }^{1,2}$. The most common of hernias, the inguinal hernia has been a common prevalent condition worldwide with an incidence of $5 \%-7 \%^{3}$. Inguinal hernias are more frequent in children ${ }^{4}$. Currently, surgical repair is the primary choice treatment for it, and approximately 20 million inguinal hernia repairs are performed worldwide annually ${ }^{5}$, which brings about a significant cost and morbidity burden worldwide.

Moreover, an increasing number of patients have undergone laparoscopic hernia repairs, such as transabdominal preperitoneal (TAPP) repair and total extraperitoneal (TEP) repair. In comparison to open repair, the morbidity and postoperative pain scores

DATE OF SUBMISSION: 09-Dec-2019

DATE OF ACCEPTANCE: 29-Dec-2019

CORRESPONDING AUTHOR: Qian Fang

Department of General Surgery, The First People's Hospital of Wenling - Chuan an South Road, 333, Wenling, Zhejiang, China - 234000

Tel: +8615169572822

E-mail: fzx120424@tom.com 
have decreased, but recovery has increased ${ }^{6,7}$. Previous studies only compare two methods ${ }^{8-10}$, and no comprehensive comparison between all these methods has been performed until now.

Therefore, the objective of this meta-analysis was to compare four methods of hernioplasty, including Mesh-plug, Lichtenstein, TAPP, and TEP. The main goal was to assess if there were differences in terms of clinical outcomes (operation time, seroma, infection, and recurrence) to provide a reliable foundation for further clinical practice.

\section{MATERIALS AND METHODS}

\section{Literature search}

To make sure the data of the studies included was veritable and reliable, we systematically searched the literature published from January 1996 to January 2017 in the Cochrane Library, Pubmed, and Embase public databases. The search terms were "inguinal hernia OR groin hernia OR hernia of groin”, "mesh-plug OR plug and patch OR perfix plug OR Rutkow-Robbins”, Lichtenstein, “TEP OR totally extraperitoneal repair", "TAPP OR transabdominal preperitoneal repair", as well as "Randomized Controlled Trial". Only articles published in English were considered.

\section{Selection criteria}

The studies were considered eligible if they met the following criteria: (1) Published in English. (2) Randomized controlled trial (RCT) design. (3) Mesh-plug, TAPP, Lichtenstein, and TEP adopted in the trials, and the outcomes mainly included operation time, seroma, infection, and recurrence rate. Studies were excluded from analysis if the papers were reviews, reports, comments, or letters.

\section{Data extraction and quality assessment}

Primarily, each article was critically reviewed separately by two authors, and then the first author's name, the year of publication, country of origin, study year, the types and methods of interventions, the patients' number, demographic characteristics of the general population, and outcomes involved were extracted and analyzed. The quality of the trials was assessed using the Cochrane Collaboration's tool ${ }^{11}$. Whenever there were disagreements in the process, a consensus was reached through pannel discussion and communication with a third investigator.

\section{Statistical analysis}

Meta-analyses were performed using the aggregate data drug information system(ADDIS) (1.16.5) based on the Bayesian framework and using Markov Chain Monte Carlo (MCMC) to evaluate the data ${ }^{12,13}$. The variables were expressed as odds ratio (OR) or mean difference (MD), with their respective $95 \%$ confidence intervals $(95 \% \mathrm{CI})$. The consistency test was analyzed by node-splitting analysis, and the consistency model was used if $\mathrm{P}>0.05$; otherwise the inconsistency model was adopted ${ }^{14}$. The Brooks-Gelman-Rubin method was applied to assess the convergence of the model with a potential scale reduction factor (PSRF) ${ }^{15}$. PSRF less than 1.2 was acceptable.

\section{RESULTS}

\section{Literature search}

The literature search and reference analysis obtained 1079 potentially eligible studies (417 Pubmed, 521 on Embase, and 141 on Cochrane Library). After removing 314 duplicated articles, 642 irrelevant studies, 44 articles including reviews, reports, comments, or letters, and 41 records, finally, 38 RCTs with 8305 participants were included in the study.

\section{Results of meta-analysis}

The parameters of ADDIS were used in our study as follows: Number of chains: 4, Tuning iterations: 20000, Simulation iterations: 50000, Thinning interval: 10, Inference samples: 10000, Variance scaling factor: 2.5. The network construction of various indicators revealed that closed networks were formed between the studies included.

\section{Operation time}

The node-splitting analysis showed the network meta-analysis appeared consistent $(\mathrm{P}>0.05$, $1.00<\mathrm{PSRF}<1.01$ ), and results from the consistency model revealed patients with the mesh-plug had shorter operation time compared to those who underwent the other three interventions, but the differences were not significant (Figure 1).

\section{Seroma}

The node-splitting analysis showed the network meta-analysis appears consistent $(\mathrm{P}>0.05$, $1.00<\mathrm{PSRF}<1.03)$. The meta-analysis with the consistency model illustrated that patients with mesh-plug had a higher incidence of postoperative seroma than 
those who underwent other interventions; however, the differences were not significant (Figure 2).

\section{Infection}

The node-splitting analysis suggested the model had good convergency and stability $(\mathrm{P}<0.05$, $1.00<\mathrm{PSRF}<1.01)$. The meta-analysis on the inconsistency model showed the infection rate in patients in the TEP group was significantly lower than that in the LR (OR=0.39, 95\% CI: 0.10-0.90, $\mathrm{P}=0.030$ ). However, there was no difference between TEP and other interventions, including Mesh-plug and TAPP (both $\mathrm{P}>0.05$ ).

\section{Recurrence}

The node-splitting analysis demonstrated the model had good convergency and stability $(\mathrm{P}>0.05$, $1.00<\mathrm{PSRF}<1.04)$. Figure 3 shows the recurrence of inguinal hernia with LR was decreased in comparison to other interventions, including mesh-plug, TAPP, and TEP, but the differences were not significant (all, $\mathrm{P}>0.05)$.

\section{DISCUSSION}

This study for the first time compared the differences of outcomes between mesh-plug, Lichtenstein, TAPP, and TEP inguinal hernia repairs based on 38 RCTs with network meta-analysis. There was no significant difference between them in aspects of operation time, seroma, infection, and recurrence, which provides a reliable foundation for further clinical practice.

Complications of inguinal hernia repair, including seroma formation and infection, have been the most common reasons for reoperation. Clinical experience indicates there is a higher frequency of seroma and wound hematoma in inguinal hernia patients with open repair. Schmedt et al. ${ }^{16}$ have demonstrated that seroma is less frequent in cases of the Lichtenstein method compared to those with endoscopic surgery. Our meta-analysis showed that there were no differences in postoperative wound complications (seroma and infection) in the mesh, Lichtenstein, TAPP, and TEP groups. A Previous study reported that TEP requires a shorter operating time than open repair, including mesh and Lichtenstein ${ }^{17}$. Moreover, Dedemadi et al. ${ }^{18}$ demonstrated that the operation time in the group of open tension-free repair is shorter than in the group of laparoscopic repair, whereas another study found no differences in the operation time
FIGURE 1. DIAGRAM OF PROBABILITY. THERE WERE NO SIGNIFICANT DIFFERENCES IN OPERATION TIME BETWEEN THE MESH-PLUG, LICHTENSTEIN, TAPP, AND TEP GROUPS.

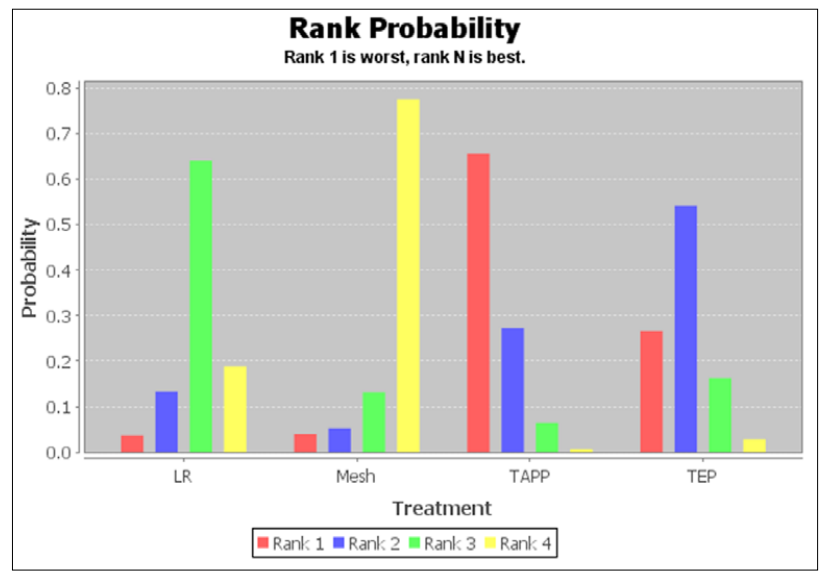

FIGURE 2. DIAGRAM OF PROBABILITY. THERE WERE NO SIGNIFICANT DIFFERENCES IN SEROMA BETWEEN THE MESH-PLUG, LICHTENSTEIN, TAPP, AND TEP GROUPS.

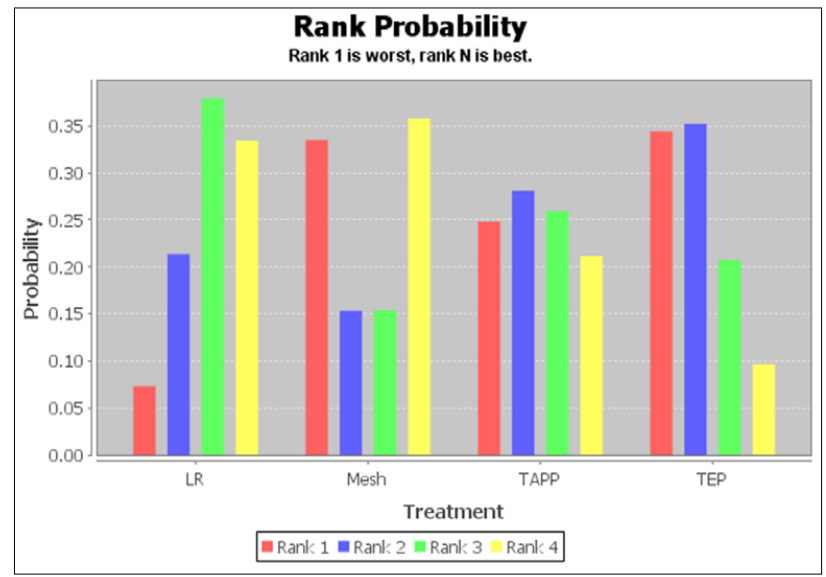

FIGURE 3. DIAGRAM OF PROBABILITY. THERE WERE NO SIGNIFICANT DIFFERENCES IN RECURRENCE BETWEEN THE MESH-PLUG, LICHTENSTEIN, TAPP, AND TEP GROUPS.

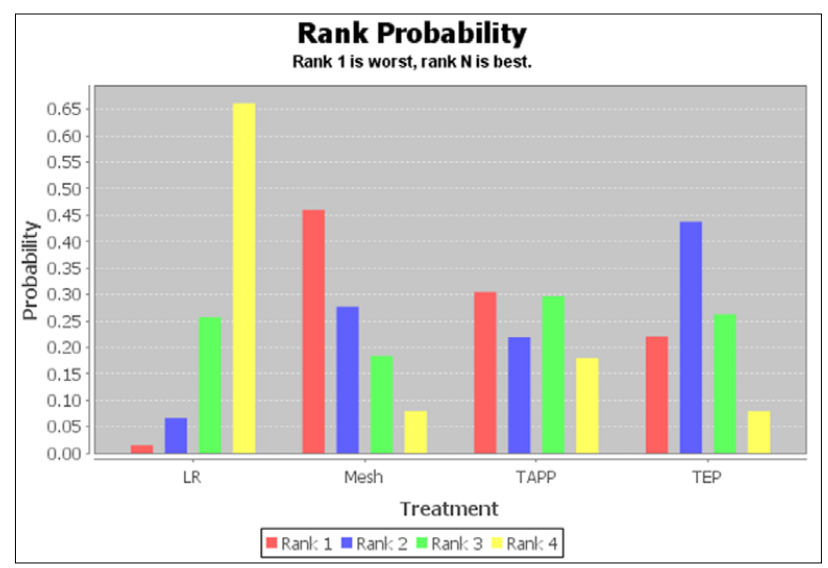


between the laparoscopic and Lichtenstein methods ${ }^{19}$. According to our results, there was no significant difference between the mesh-plug, Lichtenstein, TAPP, and TEP techniques in terms of operation time.

Recurrence, the most important aspect of clinical outcomes, is influenced by technical errors, such as improper fixation, deficiency of dissection, or inadequate repair of the hernia defect ${ }^{20}$. Previous experiences in the institute have shown that recurrence rates of patients after hernia repair are approximately $0 \sim 10 \%{ }^{9}$, and therefore, avoiding recurrence is becoming the primary issue of hernia repair. Memon et al. ${ }^{7}$ have indicated a trend of increased recurrence after laparoscopic repair. Moreover, a meta-analysis showed the recurrence rate of laparoscopic repair (both TEP and TAPP) was higher than that of open repair ${ }^{16}$. However, in the present study, we found no differences in recurrence among Mesh, Lichtenstein, TAPP, and TEP techniques.

However, there were several limitations to the present study. For example, subgroup analysis was not performed due to the incomplete research data, and in order to analyze the role of each, we analyzed only four outcome indicators. Additionally, although ADDIS was easy to operate, the results could be limited because of the inability to program freely.

In summary, the results based on the network meta-analysis demonstrated that the differences in repair outcomes between Mesh, Lichtenstein, TAPP, and TEP were not significant in the treatment of inguinal hernias. However, to further verify the results, a large number of clinical randomized controlled studies are still needed.

\section{Conflict of interest}

None.

\section{Funding}

None.

\section{Author Contributions}

Conceptualization, Qian Fang; formal analysis, Yi-Hua Shi; writing (original draft preparation), De-Shuang Xiao; writing (review and editing), Ling-Bo Dai; supervision, Ling-Bo Dai; funding acquisition, Qian Fang.

\section{RESUMO}

OBJETIVO: Comparar as abordagens de tampão com tela (mesh plug), Lichtenstein, transabdominal preperitoneal (TAPP) e totalmente extraperitoneal (TEP) em relação ao tempo de operação, seroma, infecção e recorrência no reparo de hérnias inguinais.

MÉTODOs: Estudos relevantes na literatura foram pesquisados nos bancos de dados Cochrane, PubMed e Embase. Além disso, a análise dos estudos clínicos controlados randomizados (RCTs) foi feita utilizando métodos recomendados pela Cochrane Collaboration. Os principais resultados, incluindo tempo de operação, seroma, infecção e recorrência, foram avaliados.

RESULTADOS: Um total de 38 RCTs com 3.255 pacientes foram incluídos na meta-análise. Além disso, a comparação entre mesh plug, Lichtenstein, TAPP e TEP mostrou que não havia diferenças significativas nos aspectos de tempo de operação, seroma, infecção e recorrência.

CONCLUSÕES: A meta-análise sugere que mesh plug, Lichtenstein, TAPP e TEP oferecem resultados comparáveis no reparo das hérnia inguinais em relação a tempo de operação, seroma, infecção e recorrência.

PALAVRAS-CHAVE: Hérnia inguinal/cirurgia. Resultado do tratamento. Herniorrafia. Telas cirúrgicas. Meta-análise.

\section{REFERENCES}

1. Mahmoudvand H, Forutani S, Nadri S. Comparison of treatment outcomes of surgical repair in inguinal hernia with classic versus preperitoneal methods on reduction of postoperative complications. BioMed Res Int. 2017;2017:3785302.

2. Kingsnorth $A$, LeBlanc K. Hernias: inguinal and incisional. Lancet. 2003;362(9395):1561-71.

3. Pahwa HS, Kumar A, Agarwal P, Agarwal AA. Current trends in laparoscopic groin hernia repair: a review. World J Clin Cases. 2015;3(9):789-92.

4. Ein $\mathrm{SH}, \mathrm{Njere}$ I, Ein A. Six thousand three hundred sixty-one pediatric inguinal hernias: a 35-year review. J Pediatr Surg. 2006;41(5):980-6.
5. Kalra T, Soni RK, Sinha A. Comparing early outcomes using non absorbable polypropylene mesh and partially absorbable composite mesh through laparoscopic transabdominal preperitoneal repair of inguinal hernia. J Clin Diagn Res. 2017;11(8):PC13-6.

6. Bittner R, Schwarz J. Inguinal hernia repair: current surgical techniques. Langenbecks Arch Surg. 2012;397(2):271-82.

7. Memon MA, Cooper NJ, Memon B, Memon MI, Abrams KR. Meta-analysis of randomized clinical trials comparing open and laparoscopic inguinal hernia repair. Br J Surg. 2003;90(12):1479-92. 
8. Bobo Z, Nan W, Qin Q, Tao W, Jianguo L, Xianli H. Meta-analysis of randomized controlled trials comparing Lichtenstein and totally extraperitoneal laparoscopic hernioplasty in treatment of inguinal hernias. I Surg Res. 2014;192(2):409-20.

9. Li J, Ji Z, Li Y. Comparison of mesh-plug and Lichtenstein for inguinal hernia repair: a meta-analysis of randomized controlled trials. Hernia. 2012;16(5):541-8

10. Wei FX, Zhang YC, Han W, Zhang YL, Shao Y, Ni R. Transabdominal preperitoneal (TAPP) versus totally extraperitoneal (TEP) for laparoscopic hernia repair: a meta-analysis. Surg Laparosc Endosc Percutan Tech. 2015;25(5):375-83.

11. Higgins JPT, Green S. Cochrane handbook for systematic reviews of interventions. [cited 2019 Oct 12]. Available from: https://handbook-5-1. cochrane.org/

12. Zhao J, Valkenhoef GV, De Brock B, Hillege H. ADDIS: an automated way to do network meta-analysis. [cited 2019 Oct 12]. Available from: https:// www.rug.nl/feb/research/som-research-reports/som-research-reports-2012/12007-otherdef.pdf

13. Van Valkenhoef G, Tervonen T, Zwinkels T, De Brock B, Hillege H. ADDIS: a decision support system for evidence-based medicine. Decision Support Systems. 2013;55(2):459-75.
14. Dias S, Welton NJ, Caldwell DM, Ades AE. Checking consistency in mixed treatment comparison meta-analysis. Stat Med. 2010;29(7-8):932-44.

15. Brooks SP, Gelman A. General methods for monitoring convergence of iterative simulations. J Comput Graphi Stat. 1998;7(4):434-55.

16. Schmedt CG, Sauerland S, Bittner R. Comparison of endoscopic procedures vs Lichtenstein and other open mesh techniques for inguinal hernia repair: a meta-analysis of randomized controlled trials. Surg Endosc. 2005;19(2):188-99.

17. Bringman $S$, Ramel S, Heikkinen Tl, Englund T, Westman B, Anderberg B. Tension-free inguinal hernia repair: TEP versus mesh-plug versus Lichtenstein: a prospective randomized controlled trial. Ann Surg. 2003;237(1):142-7.

18. Dedemadi G, Sgourakis G, Karaliotas C, Christofides T, Kouraklis G, Karaliotas C. Comparison of laparoscopic and open tension-free repair of recurrent inguinal hernias: a prospective randomized study. Surg Endosc. 2006;20(7):1099-104

19. Eklund A, Rudberg C, Leijonmarck CE, Rasmussen I, Spangen L, Wickbom $G$, et al. Recurrent inguinal hernia: randomized multicenter trial comparing laparoscopic and Lichtenstein repair. Surg Endosc. 2007;21(4):634-40.

20. Fitzgibbons RJ Jr, Puri V. Laparoscopic inguinal hernia repair. Am Surg. 2006;72(3):197-206 